\title{
SCIENTIFIC REPORTS

\section{OPEN A promising form-stable phase change material prepared using cost effective pinecone biochar as the matrix of palmitic acid for thermal energy storage}

\author{
Ye-chao Wan ${ }^{1}$, Yan Chen ${ }^{1}$, Zhi-xing Cui ${ }^{1}$, Han Ding ${ }^{1}$, Shu-feng Gao ${ }^{2}$, Zhi Han ${ }^{1}$ \& Jun-kai Gao ${ }^{1}$
}

A promising new form-stable phase change material (PA/PB) was fabricated using pinecone biochar (PB) as the supporting material of palmitic acid (PA). The biochar of PB with large surface area was produced by forest residue of pinecone, and it was cheap, environment friendly and easy to prepare. The PB was firstly utilized as the supporter of PA and the characterizations of PA/PB were analyzed by the BET, SEM, XRD, DSC, TGA, FT-IR and thermal conductivity tester. The results demonstrated that the PA was physically absorbed by the PB and the crystal structure of the PA was not destroyed. The results of DSC showed that the fusing and crystallization points of the form-stable phase change material with the maximum content of $\mathrm{PA}(\mathrm{PA} / \mathrm{PB}-4)$ were $59.25^{\circ} \mathrm{C}$ and $59.13^{\circ} \mathrm{C}$, and its fusing and freezing latent heat were $84.74 \mathrm{~kJ} / \mathrm{kg}$ and $83.81 \mathrm{~kJ} / \mathrm{kg}$, respectively. The results of TGA suggested that the thermal stability of the PA/PB-4 composite was excellent, which could be used for the applications of thermal energy storage. Furthermore, the thermal conductivity of PA/PB-4 was $0.3926 \mathrm{~W} /(\mathrm{m} \cdot \mathrm{K})$, which was increased by $43.76 \%$ compared with that of the pure PA. Thus, the study results indicated that the PA/PB-4 had great potential for thermal energy storage applications.

In recent years, phase change materials (PCMs) have been studied and applied extensively all over the world because of their advanced properties, such as small size change, high latent heat density and sustained phase change temperature ${ }^{1-4}$. Moreover, using PCMs can enhance energy utilization of the system ${ }^{5}$. PCMs are classified into three categories: inorganic PCMs, organic PCMs and eutectic PCMs ${ }^{6}$. Compared to the other two PCMs, organic PCMs are non-corrosive, and have high thermal stability and large latent heat ${ }^{5,7}$.

Palmitic acid (PA), as one of the ideal PCMs, has many merits such as little or no supercooling phenomenon, chemical stability, large latent heat and appropriate fusing point ${ }^{8,9}$. Therefore, a lot of researchers are attracted to investigate its application in many fields, such as smart housing, textiles and temperature-control greenhouse $\mathrm{e}^{10,11}$. However, there are two disadvantages about PA that should be overcome. One is that the thermal conversion would be weakened as a result of the low thermal conductivity of the PA. The other is that the leakage usually occurs during the phase change processes ${ }^{12}$. These drawbacks will limit the practical application of $\mathrm{PA}^{13}$. In order to resolve the above problems, the shape-stabilized PCMs composites were prepared ${ }^{14,15}$. In the shape-stabilized PCMs composites, the organic PCMs could be encapsulated by some inorganic materials, which have porous structure, large surface area and great thermal stability, such as mesoporous silica, activated carbon, diatomite and so on ${ }^{16-18}$. Han et al. used the mixture of nano- $\mathrm{SiO}_{2}$ and expanded graphite (EG) to encapsulate the paraffin under the high-temperature refining condition. The results showed that the paraffin was absorbed in nano-SiO and porous EG very well, and no leakage of melting paraffin was observed from the mixture even at $200^{\circ} \mathrm{C}$ for 1 hour ${ }^{19}$. Sharma et al. used $\mathrm{TiO}_{2}$ nanoparticles as the matrix to fabricate palmitic acid/ $/ \mathrm{TiO}_{2}$ composite, and the results suggested that the thermal conductivity of palmitic acid $/ \mathrm{TiO}_{2}$ was increased by $80 \%$ than that of the pure palmitic acid when the nanoparticle weight fraction was $5 \%{ }^{5}$. Wen et al. used diatomite as the supporting

${ }^{1}$ School of Port and Transportation Engineering, Zhejiang Ocean University, Zhoushan, 316022, China. ${ }^{2}$ Yinzhou Kefeng New Material of Polymer Co. Ltd., Ningbo, 315100, China. Correspondence and requests for materials should be addressed to Z.H. (email: hanzhi9999@163.com) or J.-k.G. (email: gaojk@zjou.edu.cn) 


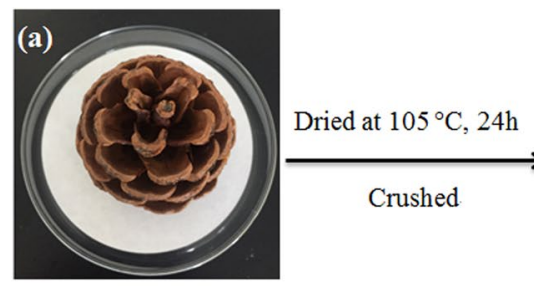

Pinecone

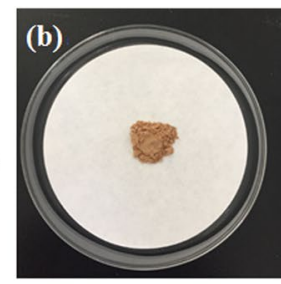

Pinecone powder

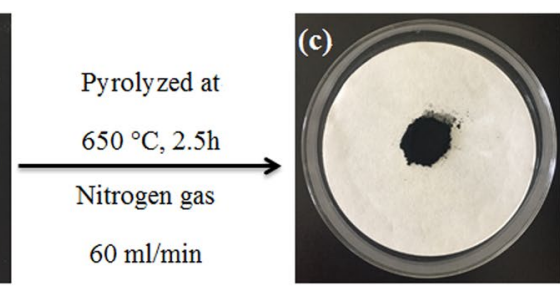

Pinecone biochar

(PB)

Figure 1. Schematic diagram of $\mathrm{PB}$ synthesization.

material to absorb the eutectic PCMs of capric acid and lauric acid. The shape-stabilized PCMs was heated to $80^{\circ} \mathrm{C}$ and refrigerated to $15^{\circ} \mathrm{C}$ as a whole thermal cycle, and they found that the melting and freezing enthalpy changed slightly after multiple thermal cycles, which indicated that the shape-stabilized PCMs had high thermal reliability ${ }^{20}$.

Activated carbon, which is derived from charcoal, has the merits of low density, high specific surface area, wide availability and great chemical stability ${ }^{21}$. Furthermore, it could hold the PCMs at stable-state and improve the thermal conversion performance ${ }^{22}$. Therefore, researchers paid much attention to study using activated carbon as the supporting material of PCMs. Chen et al. used activated carbon (AC) as the supporter of lauric acid (LA) to synthesize shape-stabilized material of LA/AC, and they found that lauric acid could be adsorbed into the activated carbon very well and the thermal conductivity of LA/AC was improved obviously compared to the pure $\mathrm{LA}^{23}$. Feng et al. used mesoporous activated carbon to prepare shape-stabilized phase change material of PEG/AC, and the results indicated that the activated carbon played a major role in preventing the leakage of PEG during the phase change process ${ }^{24}$. Yuan et al. prepared the shape-stabilized PCMs using capric-palmitic-stearic acid (CA-PA-SA) and activated carbon. They found that the heat storage time and heat release time of the shape-stabilized PCMs were reduced by $37 \%$ and $67 \%$ than that of the CA-PA-SA, which was attributed to the improvement of the thermal conductivity of shape-stabilized PCMs by the addition of activated carbon ${ }^{25}$.

However, the activated carbon has some shortcomings, such as high cost, difficult to regenerate and unrenewable $^{26}$. Biochar, which is produced from biomass residues such as forest or agriculture residues ${ }^{27}$, is cheaper, easy synthesization and renewable ${ }^{28}$. Additionally, the utilization of biochar can protect environment, because it even could be produced from food wastes ${ }^{29}$. Furthermore, the biochar also has high surface area and large sorption capacities. Therefore, a mass of studies about biochar fabrication and utilization were carried out in recent years. Wang et al. used loblolly pine wood and citrus wood to prepare biochar, and they found that the surface area of loblolly pine wood biochar (LPB) and citrus wood biochar (CTB) could be as high as $209 \mathrm{~m}^{2} / \mathrm{g}$ and $182 \mathrm{~m}^{2} / \mathrm{g}$, respectively ${ }^{30}$. Zhang et al. synthesized biochar by pyrolyzing celery-derived to absorb the $\mathrm{Pb}^{2+}$, and the results indicated that the adsorption capacity of $\mathrm{Pb}^{2+}$ by the biochar could be as high as $304 \mathrm{mg} / \mathrm{g}^{31}$. Sewu et al. pyrolyzed rice straw to fabricate the biochar of RS, and they found that the adsorption capacity of RS for cationic dye and crystal violet was higher than that of the activated carbon ${ }^{32}$. However, up to now, the study reports about utilizing biochar as the supporter of shape-stabilized phase change materials are still rare, and therefore, ongoing efforts are needed to study on the immobilization of organic phase change materials in the biochar.

Pinecone, as a residuum of pine tree, is very abundant and fairly easy to obtain in China, and therefore the price of pinecone is very cheap. Moreover, it is occasionally burned by the local people because of its limited practical application value, which could cause the air pollution ${ }^{33}$. Hence, the study on fabrication and utilization of biochar from pinecone is very meaningful. In this paper, the biochar (PB) was prepared from pinecone, and then it was firstly used as the supporting material of palmitic (PA) to synthetize shape-stabilized phase change material (PA/PB). The morphology and structural properties of $\mathrm{PA} / \mathrm{PB}$ and its thermal properties were studied. The results indicated that the $\mathrm{PA} / \mathrm{PB}$ possessed high performance in latent heat storage and had great potential in practical applications.

\section{Materials and Methods}

Materials. Pinecone was obtained from Quanzhou, Fujian Province, China. PA was purchased from Sinopharm Chemical Reagent Co., Ltd, and its melting temperature was $62-64^{\circ} \mathrm{C}$. All other reagents used in the experiment were of AR grade.

Synthesis of PB. Figure 1 shows the schematic diagram of PB synthesization. The pinecone was washed by distilled water and then it was placed into the oven for $24 \mathrm{~h}$ at $105^{\circ} \mathrm{C}$. Then, the dried sample was crushed into powders. After that the pinecone powders were pyrolyzed at $650^{\circ} \mathrm{C}$ for $2.5 \mathrm{~h}$ in a tube furnace with the protective gas (a nitrogen with the purity of $99.99 \%$ ) at the flow rate of $60 \mathrm{ml} / \mathrm{min}$. The as-prepared sample was PB.

Synthesis of PA/PB. Figure 2 shows the schematic diagram of PA/PB synthesization. The PA/PB was prepared using vacuum impregnation method. Firstly, PA was dissolved into $10 \mathrm{ml}$ absolute ethanol in the conical bottle. Secondly, PB was put into the conical bottle. Then the blend was agitated with $500 \mathrm{rpm}$ at ambient temperature under a vacuum atmosphere. After $1 \mathrm{~h}$, the conical bottle was moved to the water-bath for $4 \mathrm{~h}$ at $75^{\circ} \mathrm{C}$ under 


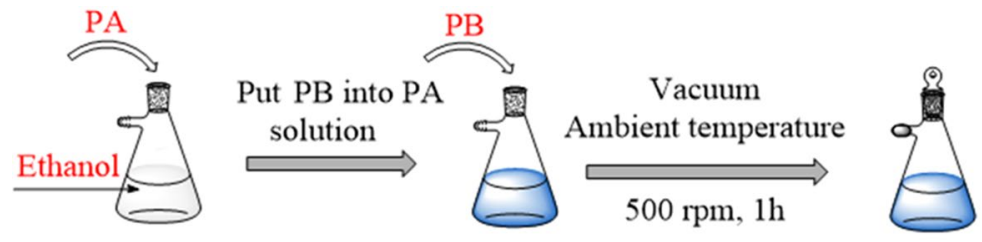

PA solution
Mixed solution

Mixed solution

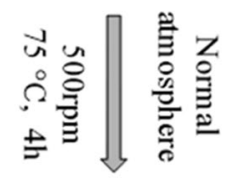

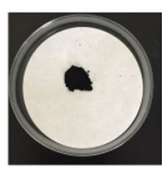

PA/PB

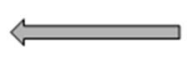

PA/PB

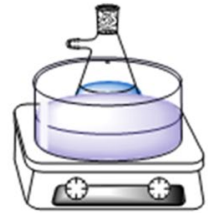

Mixed solution

Figure 2. Schematic diagram of $\mathrm{PA} / \mathrm{PB}$ synthesization.

normal atmosphere. In the following, the composite was put in the oven at $40^{\circ} \mathrm{C}$ overnight. Finally, the composite was regarded as a shape-stabilized composite if there was no leakage of melting PA from the mixture. In this study, the $\mathrm{PA}$ and $\mathrm{PB}$ were weighted with different mass ratios of 3:7, 4:6, 5:5, 6:4 and 6.5:3.5, and the corresponding composites were designated as PA/PB-1, PA/PB-2, PA/PB-3, PA/PB-4 and PA/PB-5.

Characterization. The leakage test of the pure PA and PA/PB composites were carried out by putting them into an oven for 15 minutes at $75^{\circ} \mathrm{C}$ and then they were observed whether there was any leakage of melted PA from the testing samples. The pore volume, pore diameter and surface area of the PB were measured by Brunauer-Emmett-Tellera (BET, Nova 2000e). The morphological images of PB and PA/PB composites were obtained by using the Scanning Electron Microscope (SEM, Quanta FEG 250). The crystalloid phase of the PA and the PA/PB composites were measured by the X-ray diffractometer (XRD, DX2700). The fourier transform infrared patterns of the PA and the PA/PB composites were obtained by the fourier transform infrared spectroscopy (FT-IR, Bruker, VECTOR22). The thermal stability and weight loss were measured on a thermogravimetric analysis (TGA, NETZSCH, STA449F3), and the testing temperature was from $50^{\circ} \mathrm{C}$ to $500^{\circ} \mathrm{C}$ with heating rate of $10^{\circ} \mathrm{C} / \mathrm{min}$ under protective gas of high-purity nitrogen (purity of $99.99 \%$ ). The latent heat and phase change temperature of $\mathrm{PA}$ and $\mathrm{PA} / \mathrm{PB}$ composites were investigated by using a differential scanning calorimetry (DSC, NETZSCH, 200-F3), and the heating and cooling rates were $10^{\circ} \mathrm{C} / \mathrm{min}$ with the temperature range between 0 to $100^{\circ} \mathrm{C}$ under the protective gas of high-purity nitrogen (purity of $99.99 \%$ ). The thermal conductivity of the PA and PA/PB composites were tested by the thermal conductivity meter (Foreda, CTPS-2500).

\section{Results and Discussion}

Leakage test of PA/PB. The leakage test results of the pure PA and PA/PB composites are shown in Fig. 3, and it was clear that the pure PA melted at $75^{\circ} \mathrm{C}$ (Fig. 3a) and no leakage were observed for PA/PB-1 (Fig. 3b), PA/ PB-2 (Fig. 3c), PA/PB-3 (Fig. 3d) and PA/PB-4 (Fig. 3e) composites, while the PA/PB-5 composite (Fig. 3f) had a spot of leakage at $75^{\circ} \mathrm{C}$. Hence, the PA/PB-4 composite was used as the main research object in the following experiments for the study of thermal properties of form-stable phase change material.

Characterization of PB and PA/PB-4. Figure 4 presents the SEM photographs of the PB and PA/PB-4 composite. It was known from Fig. 4(a,b) that $\mathrm{PB}$ possessed porous structures, and its pores were open to surface which could adsorb the phase change material. Figure 4(c,d) illustrate the SEM photographs of PA/PB-4 composite. In the images, it could be seen that PA was well adsorbed and filled in the PB. In Fig. 5, it could be found that there were three palpable peaks at $2.3 \mathrm{~nm}, 3.2 \mathrm{~nm}$ and $4.0 \mathrm{~nm}$ and the average pore diameter was $3.078 \mathrm{~nm}$, which suggested that the $\mathrm{PB}$ was mesoporous biochar. The pore volume and surface area of $\mathrm{PB}$ were $0.17 \mathrm{cc} / \mathrm{g}$ and $289.69 \mathrm{~m}^{2} / \mathrm{g}$. Additionally, the structural characteristic parameters of biochars prepared from different plants are shown in Table 1 . The results indicated that the PB prepared in this study was competitive, and the large pore volume and high specific surface area of $\mathrm{PB}$ were beneficial for the $\mathrm{PA} / \mathrm{PB}$ composite to preventing the leakage of melted PA in the phase change process.

XRD patterns of PB and PA/PB-4. Figure 6 exhibits the X-ray diffraction curves of pure PA, PB and $\mathrm{PA} / \mathrm{PB}-4$ composite. The XRD pattern of $\mathrm{PB}$ shows that there was a wide arc-shaped peak within the scope of 18.3-27. $7^{\circ}$, which indicated that $\mathrm{PB}$ had an amorphous structure ${ }^{23}$. The XRD pattern of PA indicates that there were two sharp peaks at $22.3^{\circ}$ and $24.2^{\circ}$, which were attributed to the regular crystallization of $\mathrm{PA}^{9}$. It could also 

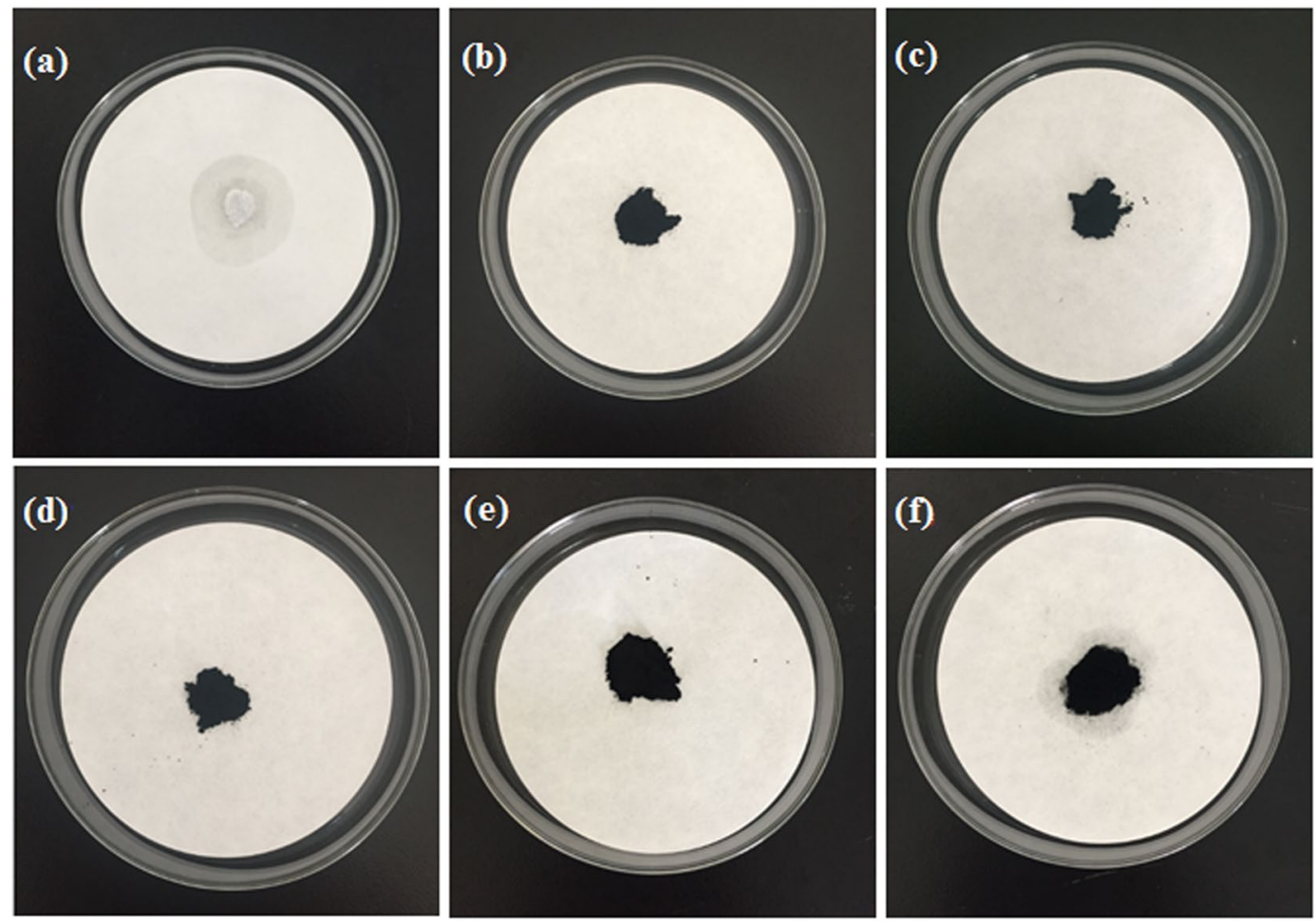

Figure 3. Leakage test of (a) PA, (b) PA/PB-1, (c) PA/PB-2, (d) PA/PB-3, (e) PA/PB-4 and (f) PA/PB-5.
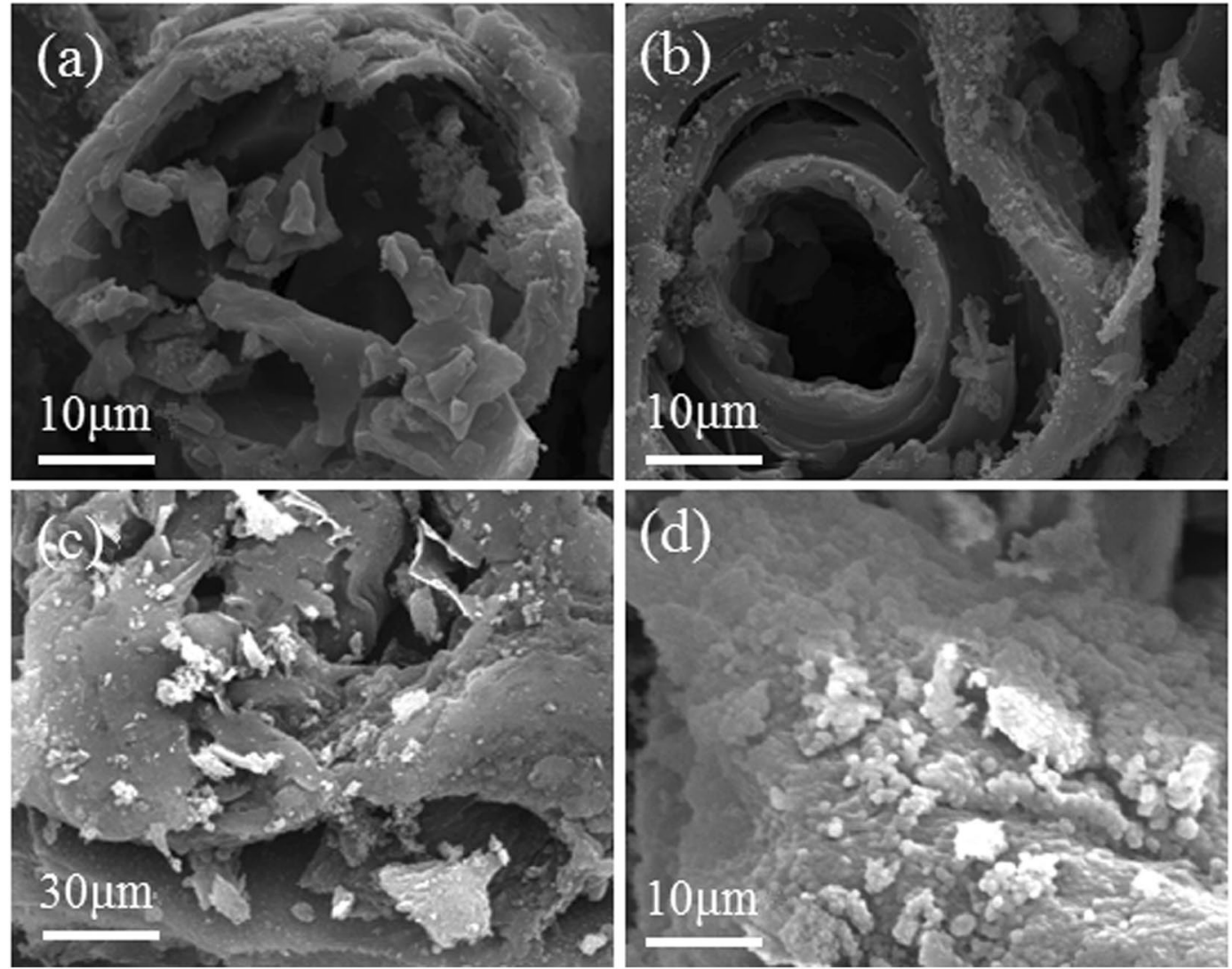

Figure 4. SEM images of (a,b) PB and (c,d) PA/PB-4. 


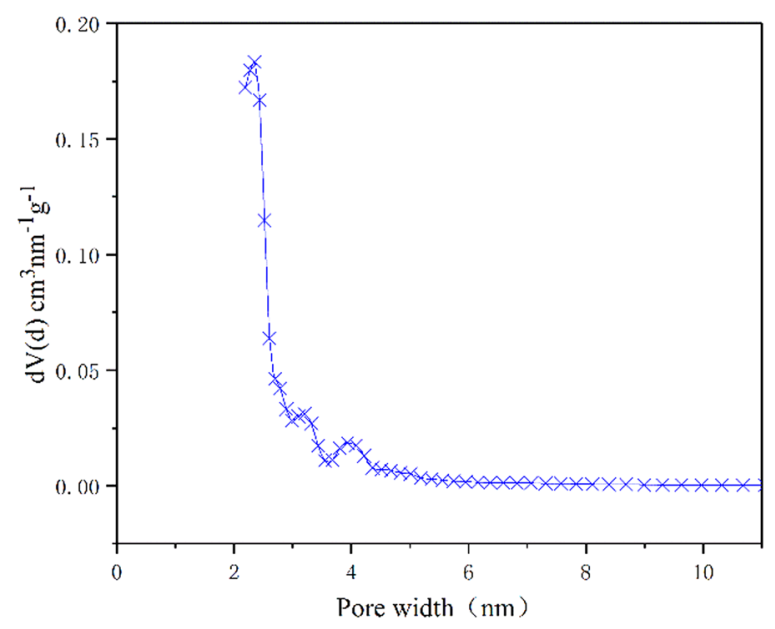

Figure 5. Pore size distribution curve of the PB.

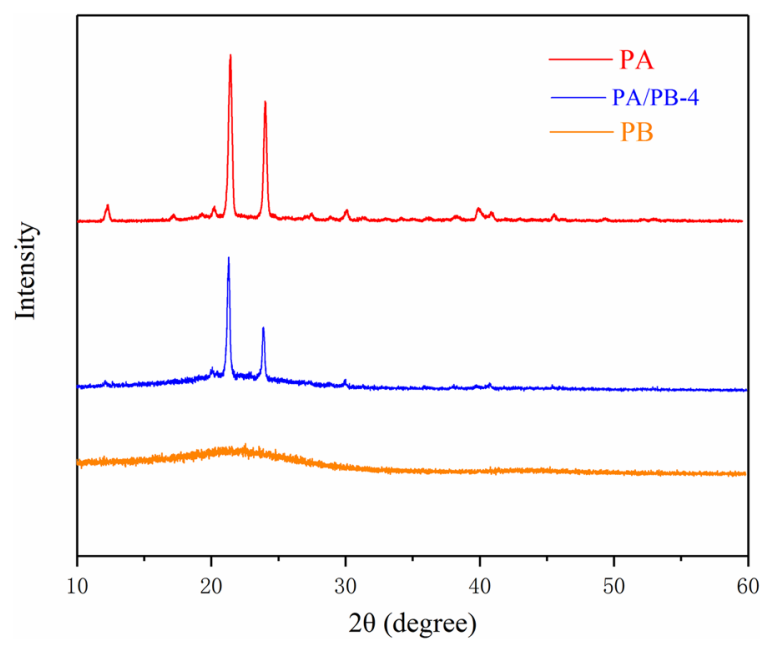

Figure 6. XRD patterns of the PA, PA/PB-4 and PB.

\begin{tabular}{|l|l|l|l|l|}
\hline Sample name & $\begin{array}{l}\text { Pore volume } \\
(\mathbf{c c} / \mathbf{g})\end{array}$ & $\begin{array}{l}\text { Pore diameter } \\
(\mathbf{n m})\end{array}$ & $\begin{array}{l}\text { Surface area } \\
\left(\mathbf{m}^{2} / \mathbf{g}\right)\end{array}$ & References \\
\hline Rapeseed stem biochar & 0.1052 & 2.20 & 316.90 & Zhao, et al. $^{43}$ \\
\hline Maize straw biochar & 0.06 & & 70.00 & Wang, et al. ${ }^{44}$ \\
\hline Castor oil cake biochar & 0.00314 & 6.9115 & 1.82 & Kalinke, et al.$^{45}$ \\
\hline Pinecone biochar & 0.17 & 3.078 & 289.69 & Present study \\
\hline
\end{tabular}

Table 1. The structural parameter of different biochars.

be seen from the XRD pattern of PA/PB- 4 that the sharp diffraction peaks at $22.3^{\circ}$ and $24.2^{\circ}$ appeared in $\mathrm{PA} / \mathrm{PB}-4$ composite, which suggested that no chemical reactions happened between $\mathrm{PA}$ and $\mathrm{PB}$, and the crystal structure of $\mathrm{PA}$ was not changed ${ }^{5}$. However, the $\mathrm{X}$-ray peaks at $22.3^{\circ}$ and $24.2^{\circ}$ of the $\mathrm{PA} / \mathrm{PB}-4$ composite were lower than that of the pure PA. It could be explained that a few crystal growth of PA in the PA/PB- 4 composite was limited by the pores of $\mathrm{PB}$ because of the hydrogen bond between the $\mathrm{PA}$ and $\mathrm{PB}^{34}$, and the schematic diagram of the interaction between the PA and PB is shown in Fig. 7.

FT-IR analysis of PA, PB and PA/PB-4. The FT-IR spectra of PA, PB and PA/PB-4 between the wave numbers of $450 \mathrm{~cm}^{-1}$ and $4000 \mathrm{~cm}^{-1}$ are shown in Fig. 8 . As seen from the spectrum of $\mathrm{PA}$, the strong peaks at $2907 \mathrm{~cm}^{-1}$ and $2847 \mathrm{~cm}^{-1}$ signified the symmetrical stretching vibration of $-\mathrm{CH}_{3}$ and $-\mathrm{CH}_{2}$ groups ${ }^{5}$. The strong peak at $1703 \mathrm{~cm}^{-1}$ was corresponded to the $\mathrm{C}=\mathrm{O}$ stretching vibration ${ }^{5}$. The peak at $1507 \mathrm{~cm}^{-1}$ represented the $\mathrm{CH}_{3}$ deformation vibration ${ }^{5}$. The absorption peaks of $1296 \mathrm{~cm}^{-1}$ and $945 \mathrm{~cm}^{-1}$ were corresponded to the in-plane 


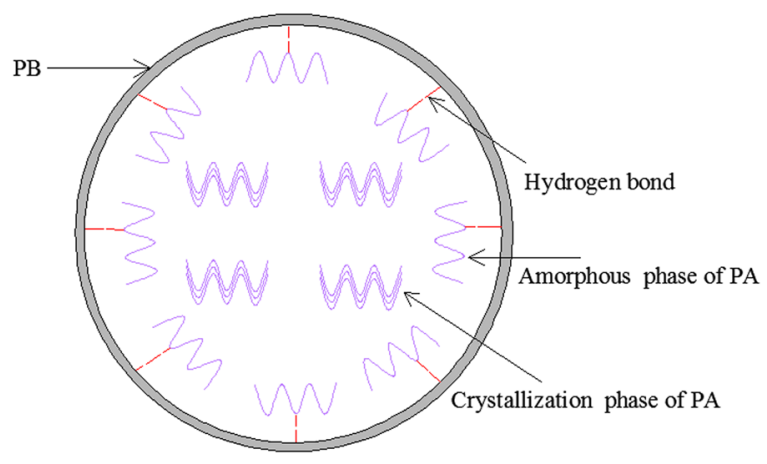

Figure 7. Schematic diagram of the interaction between PA and PB.

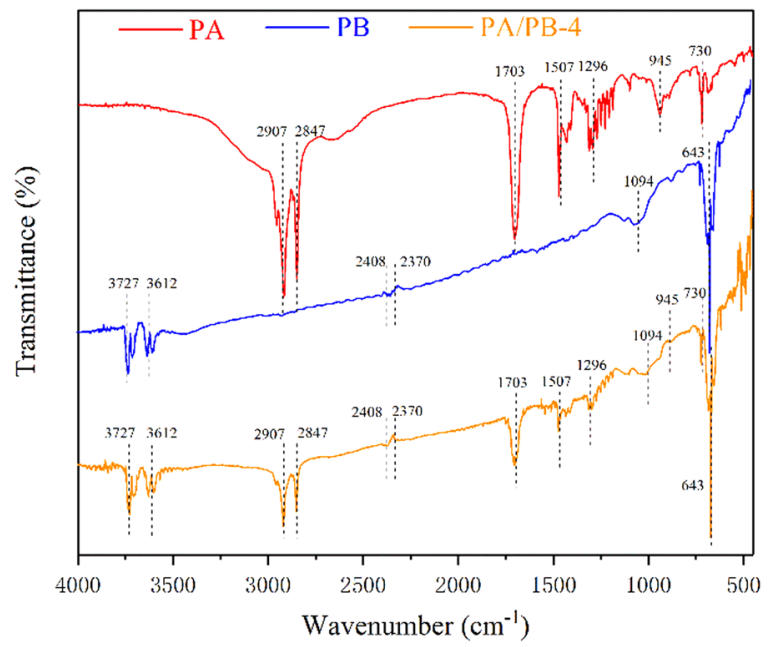

Figure 8. FT-IR spectra of PA, PB and PA/PB-4.

bending vibration and out-plane bending vibration of $-\mathrm{OH}$ group ${ }^{35}$. The peak at $730 \mathrm{~cm}^{-1}$ was due to the in-plane swinging vibration ${ }^{35}$. As can be seen from the spectrum of $\mathrm{PB}$, two strong peaks observed at $3612 \mathrm{~cm}^{-1}$ and $3727 \mathrm{~cm}^{-1}$ showed the $\mathrm{N}-\mathrm{H}$ and $\mathrm{O}-\mathrm{H}$ stretching vibrations in protein or cellulose compounds ${ }^{36}$. The peak at $2370 \mathrm{~cm}^{-1}$ was assigned to the $\mathrm{C}-\mathrm{H}$ stretching vibration of the aldehyde groups $\mathrm{s}^{37}$. The peak at $2408 \mathrm{~cm}^{-1}$ was attributed to the amine groups of proteins $\mathrm{N}-\mathrm{H}$ stretch ${ }^{36}$. The absorption peak observed at $1094 \mathrm{~cm}^{-1}$ was assigned to the stretching vibration of $\mathrm{C}-\mathrm{O}$ functional group $\mathrm{s}^{37}$. The peak at $643 \mathrm{~cm}^{-1}$ was due to the $\mathrm{O}-\mathrm{H}$ out-plane bending vibration ${ }^{38}$. It could be clearly seen from the spectrum of PA/PB-4that the peaks at $2907 \mathrm{~cm}^{-1}, 2847 \mathrm{~cm}^{-1}$, $1703 \mathrm{~cm}^{-1}, 1507 \mathrm{~cm}^{-1}, 1296 \mathrm{~cm}^{-1}, 945 \mathrm{~cm}^{-1}$ and $730 \mathrm{~cm}^{-1}$ in the spectrum of PA all appeared in the spectrum of PA/PB-4 composite, and compared to the spectra of $\mathrm{PA}$ and $\mathrm{PB}$, no new peak was found in the spectrum of $\mathrm{PA} / \mathrm{PB}-4$. The result suggested that there was no chemical reaction between the $\mathrm{PA}$ and $\mathrm{PB}$, and the interaction between the PA and PB was mainly attributed to the surface tension and capillary force between the PA and porous $\mathrm{PB}^{39}$.

Thermal stability of PA and PA/PB-4. Thermal stability was a significant parameter for the form-stable phase change materials in latent heat storage applications, and it could be measured by the TGA. As can be seen from the TGA curves of PA and PA/PB-4 in Fig. 9, the processes of weight loss of the pure PA and PA/PB-4 composite occurred in only one step, and the PA started to decompose at $168^{\circ} \mathrm{C}$ and stopped at $257^{\circ} \mathrm{C}$. As for the PA/PB-4 composite, the weights loss processes occurred between $152^{\circ} \mathrm{C}$ and $273^{\circ} \mathrm{C}$ with 57.32 wt $\%$ PA lost, and therefore, the PA/PB- 4 composite had favorable thermal stability below $152^{\circ} \mathrm{C}$, which was beneficial to the practical application of $\mathrm{PA} / \mathrm{PB}-4$ in solar based thermal energy storage $\mathrm{e}^{40}$.

Thermal properties of PA/PB composites. The DSC results of the PA/PB-1, PA/PB-2, PA/PB-3, PA/PB-4 and pure PA are shown in Figs. 10, 11 and Table 2. It can be clearly seen in Fig. 10 and Table 2, the fusing temperatures of the PA and PA/PB-1, PA/PB-2, PA/PB-3, PA/PB-4 were determined to be $62.07^{\circ} \mathrm{C}, 57.49^{\circ} \mathrm{C}, 58.11^{\circ} \mathrm{C}$, $58.77^{\circ} \mathrm{C}$ and $59.25^{\circ} \mathrm{C}$, respectively. The freezing temperatures of the PA and PA/PB-1, PA/PB-2, PA/PB-3, PA/ PB-4 were determined to be $61.79^{\circ} \mathrm{C}, 57.33^{\circ} \mathrm{C}, 57.61^{\circ} \mathrm{C}, 58.24^{\circ} \mathrm{C}$ and $59.13^{\circ} \mathrm{C}$, respectively. It could be known that the fusing temperatures and freezing temperatures of the pure PA was higher than the PA/PB composites, which might be attributed to that in the $\mathrm{PA} / \mathrm{PB}$ composite the crystalline region of $\mathrm{PA}$ became smaller while $\mathrm{PB}$ as the impurity ${ }^{24}$. As shown in Table 2, the fusing latent heats of the PA and PA/PB-1, PA/PB-2, PA/PB-3, PA/PB-4 


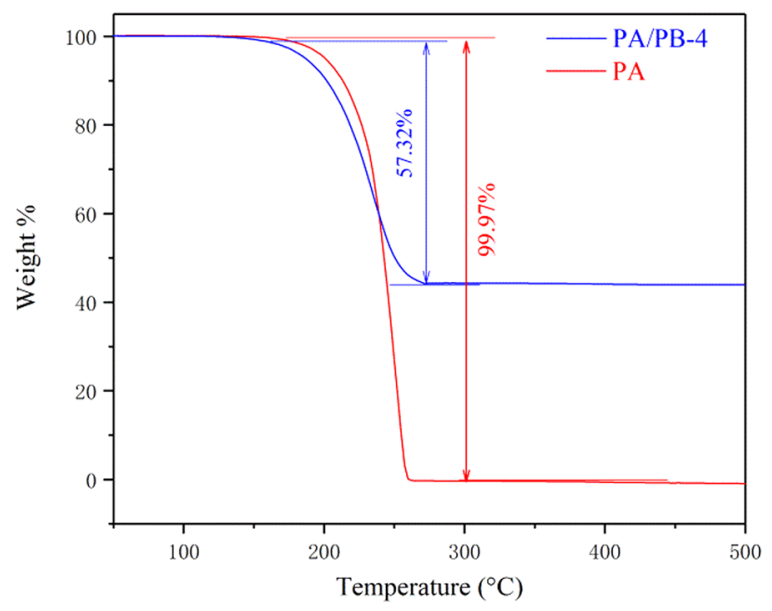

Figure 9. TGA curves of PA and PA/PB-4.

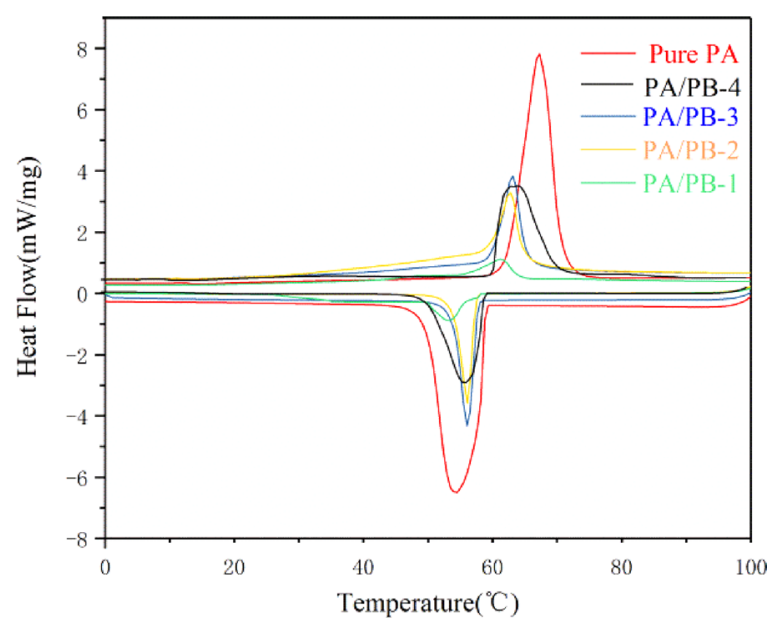

Figure 10. DSC curves of $\mathrm{PA}$ and $\mathrm{PA} / \mathrm{PB}$ composites.

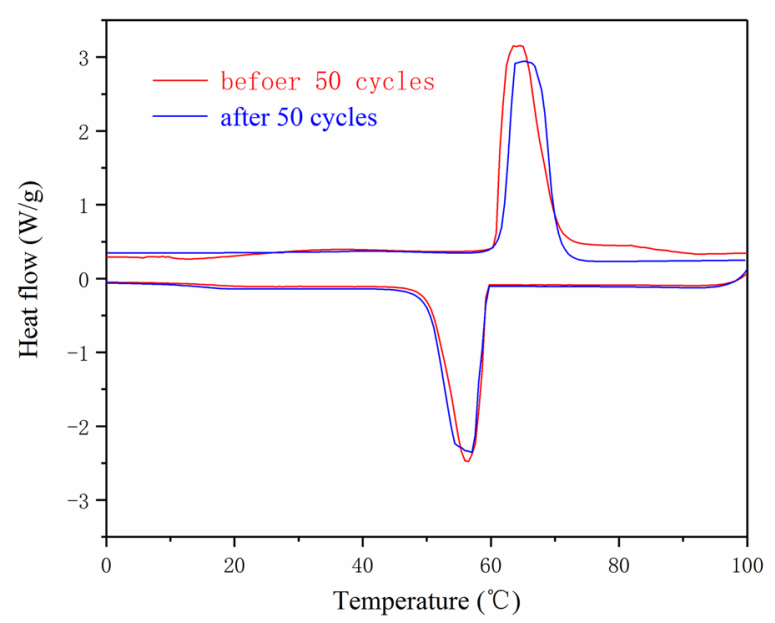

Figure 11. The enthalpy curves of the PA/PB-4 before and after 50 cycles.

were measured to be $219.63 \mathrm{~kJ} / \mathrm{kg}, 14.88 \mathrm{~kJ} / \mathrm{kg}, 43.62 \mathrm{~kJ} / \mathrm{kg}, 58.56 \mathrm{~kJ} / \mathrm{kg}$ and $84.74 \mathrm{~kJ} / \mathrm{kg}$, respectively. The solidifying latent heats of the PA and PA/PB-1, PA/PB-2, PA/PB-3, PA/PB-4 were tested to be $213.91 \mathrm{~kJ} / \mathrm{kg}, 14.86 \mathrm{~kJ} / \mathrm{kg}$, $42.82 \mathrm{~kJ} / \mathrm{kg}, 57.54 \mathrm{~kJ} / \mathrm{kg}$ and $83.81 \mathrm{~kJ} / \mathrm{kg}$, respectively. Additionally, for the PA/PB composites, the actual enthalpy 


\begin{tabular}{|c|c|c|c|c|}
\hline \multirow[b]{2}{*}{$\begin{array}{l}\text { Sample } \\
\text { name }\end{array}$} & \multicolumn{2}{|l|}{ Melting } & \multicolumn{2}{|l|}{ Freezing } \\
\hline & $\begin{array}{l}\text { Melting temperature } \\
\mathrm{T}_{\mathrm{m}}\left({ }^{\circ} \mathrm{C}\right)\end{array}$ & $\begin{array}{l}\text { Melting latent } \\
\text { heat }(\mathrm{kJ} / \mathrm{kg})\end{array}$ & $\begin{array}{l}\text { Freezing temperature } \\
T_{f}\left({ }^{\circ} \mathrm{C}\right)\end{array}$ & $\begin{array}{l}\text { Freezing latent } \\
\text { heat }(\mathrm{kJ} / \mathrm{kg})\end{array}$ \\
\hline Pure PA & 62.07 & 219.63 & 61.79 & 213.91 \\
\hline PA/PB-4 & 59.25 & 84.74 & 59.13 & 83.81 \\
\hline PA/PB-3 & 58.77 & 58.56 & 58.24 & 57.54 \\
\hline $\mathrm{PA} / \mathrm{PB}-2$ & 58.11 & 43.62 & 57.61 & 42.82 \\
\hline PA/PB-1 & 57.49 & 14.88 & 57.33 & 14.86 \\
\hline
\end{tabular}

Table 2. DSC data of the PA, PA/PB-1, PA/PB-2, PA/PB-3 and PA/PB-4.

\begin{tabular}{|l|l|l|l|l|}
\hline Sample name & $\begin{array}{l}\text { Melting temperature } \\
\mathbf{T m}\left({ }^{\circ} \mathbf{C}\right)\end{array}$ & $\begin{array}{l}\text { Latent heat } \\
(\mathbf{k J} / \mathbf{k g})\end{array}$ & $\begin{array}{l}\text { Concentration } \\
(\mathbf{w t} \%)\end{array}$ & References \\
\hline Myristic acid /high density polyethylene & 53.8 & 109.9 & 60 & Tang, et al. ${ }^{46}$ \\
\hline Diatomite/Palm Wax & 55.95 & 77.14 & - & Fort, et al. ${ }^{47}$ \\
\hline PEG2000/PAN & 54 & 70 & 50 & Sarier, et al.${ }^{48}$ \\
\hline Tween-Span/nanoSiO & & 53.77 & 20 & Zhang, et al. ${ }^{41}$ \\
\hline PA/PB & 60.33 & 84.74 & 60 & Present study \\
\hline
\end{tabular}

Table 3. Thermal properties of different composite PCMs in literature.

\begin{tabular}{|c|c|c|c|}
\hline Sample name & $\begin{array}{l}\text { Thermal conductivity } \\
\mathbf{W} /(\mathbf{m} \cdot \mathbf{K})\end{array}$ & $\begin{array}{l}\text { Concentration } \\
\text { (wt\%) }\end{array}$ & References \\
\hline $\mathrm{N}$-eicosane/CNT ${ }^{\mathrm{a}}$ & 0.32 & 60 & Karaipekli, et al. ${ }^{49}$ \\
\hline 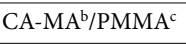 & 0.269 & - & Meng, et al. ${ }^{50}$ \\
\hline $\mathrm{CA}-\mathrm{SA}^{\mathrm{d}} / \mathrm{WCB}^{\mathrm{e}}$ & 0.38 & 72.7 & Liu, et al. ${ }^{51}$ \\
\hline $\mathrm{PA} / \mathrm{PANI}^{\mathrm{f}}$ & 0.32 & 75 & Zeng, et al. ${ }^{52}$ \\
\hline $\mathrm{PA} / \mathrm{CNTs}$ & 0.292 & 99 & Xiao, et al..$^{53}$ \\
\hline $\mathrm{PA} / \mathrm{OCNTs}^{\mathrm{g}}$ & 0.298 & 99 & Xiao, et al. ${ }^{53}$ \\
\hline $\mathrm{PA} / \mathrm{EG}^{\mathrm{h}}$ & 0.60 & 80 & Sari, et al..$^{54}$ \\
\hline $\mathrm{PA} / \mathrm{PB}-4$ & 0.3926 & 60 & Present study \\
\hline
\end{tabular}

Table 4. The thermal conductivity of different PCMs. ${ }^{a}$ carbon nanotube; ${ }^{b}$ capric-myristic acid; ${ }^{c}$ poly-methyl methacrylate; ${ }^{\mathrm{d}}$ capric-stearic acid; ${ }^{\mathrm{e}}$ white carbon black; ${ }^{\mathrm{f}}$ polyaniline; goxidized carbon nanotubes; ${ }^{\mathrm{h}}$ expanded graphite.

was lower than the theoretical enthalpy because of the hydrogen bond between the PA chains and the porous PB, which could result in drag effect on the crystallization of PA molecules ${ }^{24}$.

Figure 11 shows the enthalpy curves of the PA/PB-4 before and after 50 cycles. The results showed that the fusing point and crystallization point of the PA/PB-4 after 50 cycles had a slight change compared with that of the PA/PB-4 before the thermal cycles. Moreover, the fusing enthalpy and crystallization enthalpy changed very little before and after 50 cycles. These changes had no significant impact on the thermal properties of the PA/ PB-4. Therefore, the form-stable phase change material of PA/PB-4 prepared in this study had excellent thermal reliability.

Table 3 shows the thermal properties of form-stable phase change materials prepared with different supporters, and the results indicated that although the latent heat of PA/PB-4 prepared in this study was not the highest, it was competitive, and moreover, the supporter of $\mathrm{PB}$ was produced by forest residue of pinecone, which was cheap and environment friendly. Therefore, the PA/PB-4 had great potential for thermal energy storage applications.

Thermal conductivity of PA and PA/PB-4. The thermal conductivity of PCMs, which could affect its thermal transfer efficiently, had an important influence on its applications ${ }^{41}$. The thermal conductivities of PA, $\mathrm{PB}$ and PA/PB-4 in this study were measured to be $0.2731,0.3417$ and $0.3926 \mathrm{~W} /(\mathrm{m} \cdot \mathrm{K})$, respectively. The conductivity of $\mathrm{PB}$ was not very high, and however, it could improve the PA's conductivity effectively for the reason that when $\mathrm{PA}$ was filled into the pores of $\mathrm{PB}$, it could replace the air in the pores, and then the conductivity of PA/PB would be improved and higher than that of both $\mathrm{PA}$ and $\mathrm{PB}^{42}$. Additionally, the thermal conductivities of different form-stable phase change materials are listed in the Table 4 . It could be seen that the conductivity of PA/PB-4 prepared in this study was not the highest, and however, it was favorite. Furthermore, the matrix of PB had the merits of cheap, extensive sources, environment friendly and easy to prepare. Hence, the biochar of PB produced from forest residue of pinecone was an ideal supporting material for the preparation of form-stable phase change materials. 


\section{Conclusion}

A promising form-stable phase change material of $\mathrm{PA} / \mathrm{PB}$ was prepared by vacuum impregnation operation using pinecone biochar of $\mathrm{PB}$ as the matrix of palmitic acid. The morphology, microstructure and thermal properties of $\mathrm{PA} / \mathrm{PB}$ were studied. The results indicated that the PA was adsorbed well in the $\mathrm{PB}$ with porous structures because of the capillary force and surface tension between the PA and the porous $\mathrm{PB}$, and there was no chemical reaction between the PA and PB. The enthalpies of the fusing and freezing of PA/PB-4 were $84.74 \mathrm{~kJ} / \mathrm{kg}$ and $83.81 \mathrm{~kJ} / \mathrm{kg}$, respectively, and the thermal conductivity of $\mathrm{PA} / \mathrm{PB}-4$ was increased by $43.76 \%$ compared with that of the pure PA. Furthermore, the biochar PB, which was produced by forest residue of pinecone, was cheap, environmental friendly and easy to prepare. Therefore, the PA/PB prepared in this study had great potential for thermal energy storage applications.

\section{References}

1. Shobo, A. B. et al. Rapid thermal cycling of three phase change materials (PCMs) for cooking applications. Journal of the Brazilian Society of Mechanical Sciences and Engineering 40, 329-341 (2018).

2. Li, L. et al. Research on composite-phase change materials (PCMs)-bricks in the west wall of room-scale cubicle: Mid-season and summer day cases. Building and Environment 123, 494-503 (2017).

3. Wang, L. L. et al. Method for Control of Particle Size and Morphology of Paraffin/Polystyrene-Divinylbenzene Microcapsules. China Petroleum Processing and Petrochemical Technology 18, 73-82 (2016).

4. Lin, Y. X. et al. Palmitic acid/polyvinyl butyral/expanded graphite composites as formstable phase change materials for solar thermal energy storage. Applied Energy 228, 1801-1809 (2018).

5. Sharma, R. K. et al. Thermal properties and heat storage analysis of palmitic acid-TiO2 composite as nano-enhanced organic phase change material (NEOPCM). Applied Thermal Engineering 99, 1254-1262 (2016).

6. Cunha, J. P. D. \& Eames, P. Thermal energy storage for low and medium temperature applications using phase change materials -A review. Applied Energy 177, 227-238 (2016).

7. Chung, O. et al. Thermal performance of organic PCMs/micronized silica compositefor latent heat thermal energy storage. Energy and Buildings 70, 180-185 (2014).

8. Wei, D. W. et al. Solid-liquid phase equilibria of (n-octadecane with myristic, and palmitic acid) binary mixtures used as phase change materials (PCMs). The Journal of Chemical Thermodynamics 101, 7-11 (2016).

9. Fang, G. Y. et al. Preparation and thermal properties of form-stable palmitic acid/active aluminum oxide composites as phase change materials for latent heat storage. Materials Chemistry and Physics 137, 558-564 (2012).

10. Sharma, R. K. et al. Developments in organic solid-liquid phase change materials and their applications in thermal energy storage. Energy Conversion and Management 95, 193-228 (2015).

11. Alva, G. et al. Synthesis and characterization of microencapsulated myristic acid-palmitic acid eutectic mixture as phase change material for thermal energy storage. Applied Energy 203, 677-685 (2017).

12. Qian, Z. C. et al. Phase change materials of paraffin in h-BN porous scaffolds withenhanced thermal conductivity and form stability. Energy and Buildings 158, 1184-1188 (2018).

13. Cai, Y. B. et al. Influences of expanded graphite on structural morphology and thermal performance of composite phase change materials consisting of fatty acid eutectics and electrospun PA6 nanofibrous mats. Renewable Energy 57, 163-170 (2013).

14. Ren, Y. X. et al. $\mathrm{Ca}\left(\mathrm{NO}_{3}\right)_{2}-\mathrm{NaNO}_{3}$ /expanded graphite composite as a novel shape-stable phase change material for mid-to hightemperature thermal energy storage. Energy Conversion and Management 163, 50-58 (2018).

15. Liang, K. et al. Fabrication of shape-stable composite phase change materials based on lauric acid and graphene/graphene oxide complex aerogels for enhancement of thermal energy storage and electrical conduction. Thermochimica Acta 664, 1-15 (2018).

16. Reichartd, C. et al. Highly stable adsorptive and covalent immobilization of Thermomyceslanuginosus lipase on tailor-made porous carbon material. Biochemical Engineering Journal 138, 63-73 (2018).

17. Kang, Y. J. et al. Energy efficient Bio-based PCM with silica fume composites to apply in concrete for energy savingin buildings. Solar Energy Materials \& Solar Cells 143, 430-434 (2015).

18. Qian, T. T. et al. Diatomite: A promising natural candidate as carrier material for low, middle and high temperature phase change material. Energy Conversion and Management 98, 34-45 (2015).

19. Han, X. et al. Preparation and characterization of high-temperature non-flowing SiO2/EG/paraffin composites by high-temperature refining. Colloids and Surfaces A 542, 1-7 (2018).

20. Wen, R. L. et al. Preparation and thermal properties of fatty acid/diatomite form-stable composite phase change material for thermal energy storage. Solar Energy Materials and Solar Cells 178, 273-279 (2018).

21. Zhu, X. Z. et al. Facile synthesis of hierarchical porous carbon material by potassium tartrate activation for chloramphenicol removal. Journal of the Taiwan Institute of Chemical Engineers 85, 141-148 (2018).

22. Xiao, X. et al. Morphologies and thermal characterization of paraffin/carbon foam composite phase change material. Solar Energy Materials \& Sola rCells 117, 451-461 (2013).

23. Chen, Z. et al. Synthesis and thermal properties of shape-stabilized lauricacid/activated carbon composites as phase change materials for thermal energy storage. Solar Energy Materials \& Solar Cells 102, 131-136 (2012).

24. Feng, L. L. et al. Preparation and characterization of polyethylene glycol/active carbon composites as shape-stabilized phase change materials. Solar Energy Materials \& Solar Cells 95, 644-650 (2011).

25. Liu, F. L. et al. Preparation and properties of capric-stearic acid/White Carbon Black composite for thermal storage in building envelope. Energy and Buildings 158, 1781-1789 (2018).

26. Dawood, S. et al. Synthesis and characterization of slow pyrolysis pine cone bio-char in the removal of organic and inorganic pollutants from aqueous solution by adsorption: Kinetic, equilibrium, mechanism and thermodynamic. Bioresource Technology 246, 76-81 (2017).

27. Hagemann, N. et al. Activated Carbon, Biochar and Charcoal: Linkages and Synergies across Pyrogenic Carbon's ABCs. Water 10, 182-201 (2018).

28. Magnacca, G. et al. Preparation, characterization and environmental/electrochemical energy storage testing of low-cost biochar from natural chitin obtained via pyrolysis at mild conditions. Applied Surface Science 427, 883-893 (2018).

29. Rago, Y. P. et al. Assessing the potential of biofuel (biochar) production from food wastes through thermal treatment. Bioresource Technology 248, 258-264 (2017).

30. Wang, S. S. et al. Physicochemical and sorptive properties of biochars derived from woody and herbaceous biomass. Chemosphere 134, 257-262 (2015).

31. Zhang, T. et al. Efficient removal of lead from solution by celery-derived biochars rich in alkaline minerals. Bioresource Technology 235, 185-192 (2017).

32. Sewu, D. D. et al. Highly efficient adsorption of cationic dye by biochar produced with Korean cabbage waste. Bioresource Technology 224, 206-213 (2017).

33. Zhang, Z. Q. et al. Optimization of the Extraction Process for Shikimic Acid from the pinecone of Pinus yunnanensis Franch. Medicinal Plant 2, 66-68 (2011). 
34. Wang, C. Y. et al. Shape-stabilized phase change materials based on polyethylene glycol/porous carbon composite: The influence of the pore structure of the carbon materials. Solar Energy Materials \& Solar Cells 105, 21-26 (2012).

35. Mehrali, M. et al. Preparation and characterization of palmitic acid/graphene nanoplatelets composite with remarkable thermal conductivity as a novel shape-stabilized phase change material. Applied Thermal Engineering 61, 633-640 (2013).

36. Veni, D. K. et al. Biochar from green waste for phosphate removal with subsequent disposal. Waste Management 68, 752-759 (2017).

37. Khadiran, T. et al. Shape-stabilised n-octadecane/activated carbon nanocomposite phase change material for thermal energy storage. Journal of the Taiwan Institute of Chemical Engineers 55, 189-197 (2015).

38. Dodevski, V. et al. Plane tree seed biomass used for preparation of activated carbons (AC) derived from pyrolysis. Modeling the activation process. Colloids and Surfaces A: Physicochem. Eng. Aspects 522, 83-96 (2017).

39. Wang, C. L. et al. A quick-fix design of phase change material by particle blending and spherical agglomeration. Applied Energy 191, 239-250 (2017)

40. Du, K. et al. A review of the applications of phase change materials in cooling, heating and power generation in different temperature ranges. Applied Energy 220, 242-273 (2018).

41. Zhang, X. Y. et al. PCM-in-watere mulsion for solar thermal applications: The effects of emulsifiers and emulsification conditions on thermal performance. Solar Energy Materials \& Solar Cells 147, 211-224 (2016).

42. Chen, Y. et al. Cost-Effective biochar produced from agricultural residues and its application for preparation of high performance Form-Stable phase change material via simple method. International Journal of Molecular Sciences 19, 3055 (2018).

43. Zhao, B. et al. Effect of pyrolysis temperature, heating rate, and residence time on rapeseed stem derived biochar. Journal of Cleaner Production 174, 977-987 (2018).

44. Wang, X. B. et al. Characteristics of maize biochar with different pyrolysis temperatures and its effects on organic carbon, nitrogen and enzymatic activities after addition to fluvo-aquic soil. Science of the Total Environment 538, 137-144 (2015).

45. Kalinke, C. et al. Biochar prepared from castor oil cake at different temperatures: A voltammetric study applied for $\mathrm{Pb}^{2+}, \mathrm{Cd}^{2+}$ and $\mathrm{Cu}^{2+}$ ionspreconcentration. Journal of Hazardous Materials 318, 526-532 (2016).

46. Tang, Y. J. et al. Synthesis and thermal properties of the MA/HDPE composites with nano-additives as form-stable PCM with improved thermal conductivity. Applied Energy 180, 116-129 (2016).

47. Fort, J. et al. Diatomite/Palm Wax Composite as a Phase Change Material for Latent Heat Storage. Advanced Materials Research 1126, 33-38 (2015)

48. Sarier, N. et al. Production of PEG grafted PAN copolymers and their electrospunnanowebs as novel thermal energy storage materials. Thermochimica Acta 643, 83-93 (2016).

49. Karaipekli, A. et al. Thermal characteristics of expanded perlite/paraffin composite phase change material with enhanced thermal conductivity using carbon nanotubes. Energy Conversion and Management 134, 373-381 (2017).

50. Meng, D. \& Wang, L. J. Characterization and thermal conductivity of modified graphite/fatty acid eutectic/PMMA form-stable phase change material. Journal of Wuhan University of Technology-Mater. Sci. Ed 28, 586-591 (2013).

51. Liu, F. L. et al. Preparation and properties of capric-stearic acid/White Carbon Black composite for thermal storage in building envelope. Energy and Buildings 158, 1781-1789 (2018).

52. Zeng, J. L. et al. Preparation and thermal properties of palmitic acid/polyaniline/exfoliated graphite nanoplatelets form-stable phase change materials. Applied Energy 115, 603-609 (2014).

53. Xiao, D. et al. Study on the phase change thermal storage performance of palmitic acid/carbon nanotubes composites. Composites: Part A 77, 50-55 (2015)

54. Ahmet, S. \& Ali, K. Preparation, thermal properties and thermal reliability of palmitic acid/expanded graphite composite as formstable PCM for thermal energy storage. Solar Energy Materials \& Solar Cells 93, 571-576 (2009).

\section{Acknowledgements}

The authors are grateful for the financial supports of the Zhejiang Provincial Natural Science Foundation of China (No. LY18E060007), National Sparking Plan Project (No. 2013GA700254), Zhejiang Provincial Public Projects of China (No. 2017C31008), Science and Technology Planning Project of Zhoushan of China (No. 2016C41004, 2018C21017), the National Natural Science Foundation of China (No. 51606168).

\section{Author Contributions}

Y.C.W., J.K.G. and Z.H. conceived and designed the experiments. Y.C.W., Y.C., Z.X.C. and H.D. carried out the experiments. Y.C.W., J.K.G., Y.C. and Z.H. analyzed the data and wrote the manuscript text. J.K.G., Y.C.W., S.F.G., Z.H. and Y.C. discussed the results and reviewed the manuscript.

\section{Additional Information}

Competing Interests: The authors declare no competing interests.

Publisher's note: Springer Nature remains neutral with regard to jurisdictional claims in published maps and institutional affiliations.

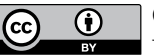

Open Access This article is licensed under a Creative Commons Attribution 4.0 International

License, which permits use, sharing, adaptation, distribution and reproduction in any medium or format, as long as you give appropriate credit to the original author(s) and the source, provide a link to the Creative Commons license, and indicate if changes were made. The images or other third party material in this article are included in the article's Creative Commons license, unless indicated otherwise in a credit line to the material. If material is not included in the article's Creative Commons license and your intended use is not permitted by statutory regulation or exceeds the permitted use, you will need to obtain permission directly from the copyright holder. To view a copy of this license, visit http://creativecommons.org/licenses/by/4.0/.

(C) The Author(s) 2019 